\title{
Removal of zinc(II) ion by graphene oxide (GO) and functionalized graphene oxide-glycine (GO-G) as adsorbents from aqueous solution: kinetics studies
}

\author{
F. Najafi ${ }^{1}$
}

Received: 8 December 2014/ Accepted: 7 May 2015/Published online: 30 May 2015

(c) The Author(s) 2015. This article is published with open access at Springerlink.com

\begin{abstract}
The main purpose of this study is to explain the absorption of zinc from aqueous solution by grapheme oxide and functionalized grapheme oxide with glycine as the adsorbent surface. For confirmed functionalized graphene oxide, the glycine amino group was added to the surface of graphene oxide. The effects of the initial concentration of $\mathrm{Zn}(\mathrm{II})$ ions and contact time were studied. Results showed that with increasing initial concentration of $\mathrm{Zn}$ (II) ions, the adsorption capacity increased. The adsorption capacity did not show a large change after $50 \mathrm{~min}$; therefore, for the study of kinetic parameters, the optimal time of 50 min was selected. The chemical structure of graphene oxide was confirmed by using FT-IR analysis. The adsorption process of $\mathrm{Zn}$ (II) ions graphene oxide and functionalized graphene oxide-glycine surfaces was fixed at $298 \mathrm{~K}$ and $\mathrm{pH} 6$. The pseudo-first-order and the pseudo-second-order (types I, II, III and IV) kinetic models were tested for the adsorption process and the results showed that the kinetic parameters best fit type (I) of the pseudo-second-order model. A high $R^{2}$ was used to be the best match.
\end{abstract}

Keywords Graphene oxide - Glycine · Amino functionalization $\cdot \mathrm{Zn}(\mathrm{II})$ ions $\cdot$ Adsorption $\cdot$ Kinetic

\section{Introduction}

In recent years, heavy metal contamination in wastewater has become a major subject. Heavy metals in nature are hazardous to plants, animals, and humans even in slight

\section{F. Najafi}

fahimnajafi@gmail.com

1 Department of Chemistry, Roudehen Branch, Islamic Azad University, Roudehen, Iran concentrations. Therefore, the concentrations of ions of heavy metals solvable in effluents must be controlled well to prevent their toxicity effects. Chemists are trying to find ways to remove pollutants and contaminants. Among many heavy metals, zinc is one of the common pollutants in different industrial effluents. Zinc (ion) is usually found in industrial wastewater such as acid mine drainage, galvanizing plants, municipal and also natural materials. Many methods including physical and chemical methods, such as chemical precipitation [1], filter media [2], biosorption [3], flocculation [4] and ion exchange [5], have been used to solve this problem by removing heavy metals from wastewater. One of the most common methods is adsorption due to its easiness and simplicity. A study of the literature shows which diverse synthetic and natural adsorbents had been used for the adsorption of zinc from aqueous solution $[6,7]$. However, adsorption is the maximum common, effective removal method, for many low-level pollutants.

Graphene (Gr), a single layer of sp2-hybridized carbon atoms in a closely packed honeycomb two-dimensional lattice, has attracted enormous attentions since its discovery in 2004 [8]. One of the most commonly used derivatives of graphene is graphene oxide (GO). One of the important structural elements of graphite is GO that is bound together by van der Waals forces. GO has attracted a lot attention because of its capability and usages in energy storage, electronics and water treatment membranes [9].

In this study, we investigated the adsorption of $\mathrm{Zn}$ (II) by graphene oxide and functionalized graphene oxide-glycine. Also, the effect of parameter contact time on $\mathrm{Zn}$ (II) ions adsorption was studied. For characterizing the surface of adsorbents, the FT-IR technique was used. Before and after the adsorption process, infrared spectra of the adsorbent and metal-loaded adsorbent samples were recorded in the range 4000 to $500 \mathrm{~cm}^{-1}$. 


\section{Experimental}

\section{Materials and methods}

All experiments were conducted in a closed $250 \mathrm{~mL}$ pyramid glass bottle, and $\mathrm{HCl}$ or $\mathrm{NaOH} 0.1 \mathrm{M}$ (provided by Merck Company with maximum purity) was used to adjust the $\mathrm{pH}$ of the solution. Zinc nitrate hexahydrate (reagent grade $98 \%$, CAS Number 10196-18-6, linear formula $\mathrm{Zn}\left(\mathrm{NO}_{3}\right)_{2} \cdot 6 \mathrm{H}_{2} \mathrm{O}$, molecular weight 297.49) was obtained from Sigma-Aldrich. Graphene oxide (composition: carbon (79\%), oxygen (20\%), flake size $0.5-5 \mu \mathrm{m}$, thickness 1 atomic layer-at least $80 \%$ ) was purchased from Supermarket USA. Glycine (CAS Number 56-40-6, impurities $\leq 0.01 \%$ insoluble matter, $p \mathrm{~K}_{\mathrm{a}}\left(25^{\circ} \mathrm{C}\right)=2.35$, M.P $=240{ }^{\circ} \mathrm{C}$ ), $N, N$-dimethylformamide (DMF, $99.9 \%$ ), 1-ethyl-(3-3-dimethylaminopropyl) carbodiimide (EDC, $99 \%$ ) and $N$-hydroxysuccinimide (NHS, $99.9 \%$ ) were obtained from Sigma-Aldrich.

FT-IR spectroscopy from Perkin Elmer-E100 Company was used within $400-4000 \mathrm{~cm}^{-1}$. At the end of the equilibrium period, the suspensions were centrifuged at $3500 \mathrm{rpm}$ for $10 \mathrm{~min}$, and the supernatant was then filtered through $0.2 \mu \mathrm{m}$ filter paper (Gelmen Sciences) for later analysis of the atomic absorption spectrophotometry (AAS) (Perkin Elmer Analyst 700). The difference between the initial and the equilibrium $\mathrm{Zn}(\mathrm{II})$ ion concentration determines the amount of $\mathrm{Zn}$ (II) ion adsorbed on GO-G and GO as adsorbent surfaces. Each experiment was performed twice and experimental results were average values. Doubly distilled water was used and all adsorbents were washed before use. Ultrasonic bath (71020-DTH-E; Model 1510 DTH, 220V; EMS Company, Hatfield, PA) was used to mix the particles of GNPs and SWCNTs were used to aggregate and to form the bulk.

\section{Preparation of GO and GO-G surfaces}

In this study, we synthesized graphene oxide-glycine (GO$\mathrm{G})$ powders via condensation reaction between graphene oxide (GO) powder and glycine and using FT-IR to characterize the presence of glycine on the GO surface as adsorbent.

GO (45 mg) was obtained by the reaction of $40 \mathrm{mg}$ glycine in ethanol with the aid of coupling agents, EDC $(50 \mathrm{mg})$ and NHS $(25 \mathrm{mg})$, at $70{ }^{\circ} \mathrm{C}$ for $36 \mathrm{~h}$. At the end of the reaction, GO-G-SH nanocomposite was then purified by filtering through a $0.22 \mu \mathrm{m}$ membrane, followed by washing with copious amounts of ethanol and water $[1: 1(\mathrm{v} / \mathrm{v})]$ and then drying at $85^{\circ} \mathrm{C}$ for $36 \mathrm{~h}$. GO-G-SH nanocomposite surfaces were used as an adsorbent for $\mathrm{Zn}$ (II) ion removal from aqueous solution (Scheme 1).

\section{Zn(II) ions adsorption study}

For adsorption of zinc by graphene oxide and functionalized GO-G from aqueous solutions, $20 \mathrm{mg}$ of adsorbents was added to $20 \mathrm{~mL}$ of $\mathrm{Zn}$ (II) ion solution with known initial concentration $(15 \mathrm{ppm})$. The contact time of adsorption $\mathrm{Zn}(\mathrm{II})$ ions on graphene oxide and functionalized GO-G was confirmed by preliminary experiments to be $50 \mathrm{~min}$ at $298 \mathrm{~K}$ and $\mathrm{pH}$ 6. After $50 \mathrm{~min}, \mathrm{Zn}$ (II) ions were removed from the solution by graphene oxide and functionalized GO-G. The bottles of solutions were placed in an ultrasonic that was operated at defined temperatures and times and the remaining concentration of $\mathrm{Zn}$ (II) ions was determined by atomic absorbance spectrophotometry AAS (Perkin Elmer A Analyst 700) to calculate the removal of $\mathrm{Zn}$ (II) ions by graphene oxide and functionalized GO-glycine using the following expression Eq. (1) [10]:

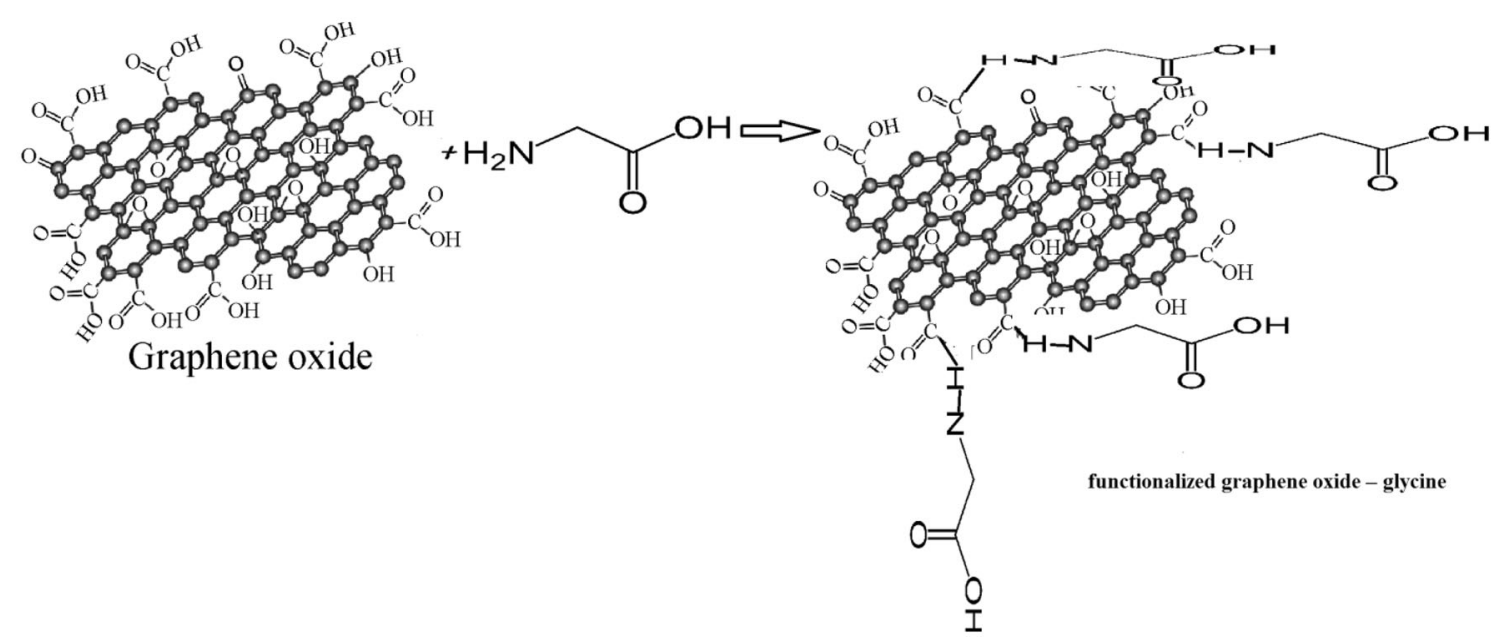

Scheme 1 Reaction between graphene oxide and glycine to functionalize graphene oxide-glycine (GO-G) 
$q_{\mathrm{e}}=\left(\frac{C_{0}-C_{\mathrm{e}}}{W}\right) \times V$,

where $q_{\mathrm{e}}\left(\mathrm{mg} \mathrm{g}^{-1}\right)$ is the amount of $\mathrm{Zn}(\mathrm{II})$ ions taken up by the adsorbents, $C_{0}\left(\mathrm{mg} \mathrm{L}^{-1}\right)$ represents the initial $\mathrm{Zn}$ (II) ion concentration, $C_{\mathrm{e}}\left(\mathrm{mg} \mathrm{L}^{-1}\right)$ the equilibrium concentration of the $\mathrm{Zn}(\mathrm{II})$ ions remaining in the solution, $W(\mathrm{~g})$ the adsorbent mass and $V(\mathrm{~L})$ the volume of the aqueous solution [11].

\section{Kinetic experiments}

For the determination of the effect of time on the adsorption of $\mathrm{Zn}(\mathrm{II})$ ions at an initial concentration of $15 \mathrm{ppm}$ by graphene oxide and functionalized $\mathrm{GO}-\mathrm{G}$ surfaces prepared Zinc samples by adding $20 \mathrm{mg}$ of graphene oxide and functionalized $\mathrm{GO}-\mathrm{G}$ adsorbents into $20 \mathrm{~mL}$ of $\mathrm{Zn}$ (II) ions aqueous solutions after a certain period of time at 10,20, 30, 40, 50, 60 and $70 \mathrm{~min}$ the samples were collected and the concentration of $\mathrm{Zn}$ (II) ions in the aqueous solutions were determined using the atomic absorbance spectrophotometry AAS (Perkin Elmer A Analyst 700$)$ was measured $( \pm 0.01 \%)$. These result $s$ showed that the removal of zinc happened within the initial few minutes and the adsorbed quantity of $\mathrm{Zn}$ (II) ions reached its equilibrium amount very rapidly. The equilibrium time for adsorption of $\mathrm{Zn}$ (II) ions was about $50 \mathrm{~min}$.

The $\mathrm{Zn}(\mathrm{II})$ ion adsorption capacity at time $t\left(q_{t}\right)$, in $\mathrm{mg} /$ g, was then calculated using Eq. (2) [9]:

$q_{t}\left(\frac{C_{0}-C_{t}}{W}\right) \times V$

where $C_{0}\left(\mathrm{mg} \mathrm{L}^{-1}\right)$ is the initial $\mathrm{Zn}(\mathrm{II})$ ion concentration, $C_{t}\left(\mathrm{mg} \mathrm{L}^{-1}\right)$ the $\mathrm{Zn}(\mathrm{II})$ ion concentration at time $t$, $W(\mathrm{~g})$ the adsorbent mass and $V(\mathrm{~L})$ the volume of $\mathrm{Zn}(\mathrm{II})$ ion solution.

\section{Characterization}

The functional groups were characterized using a Perkin Elmer-E100, $2 \mathrm{~m}^{-1}$ resolution) Spectra were acquired in the $4000-400 \mathrm{~cm}^{-1}$ range (Fig. 3).

\section{Result and discussions}

\section{Characterizations of adsorbents}

FT-IR spectra of the graphene oxide and GO-G nanocomposite were obtained Fig. 1. The FT-IR spectrum is illustrated in Fig. 1. For graphene oxide, peaks at 3432 and $1711 \mathrm{~cm}^{-1}$ were related to $-\mathrm{OH}$ and $\mathrm{C}=\mathrm{O}$ bands,
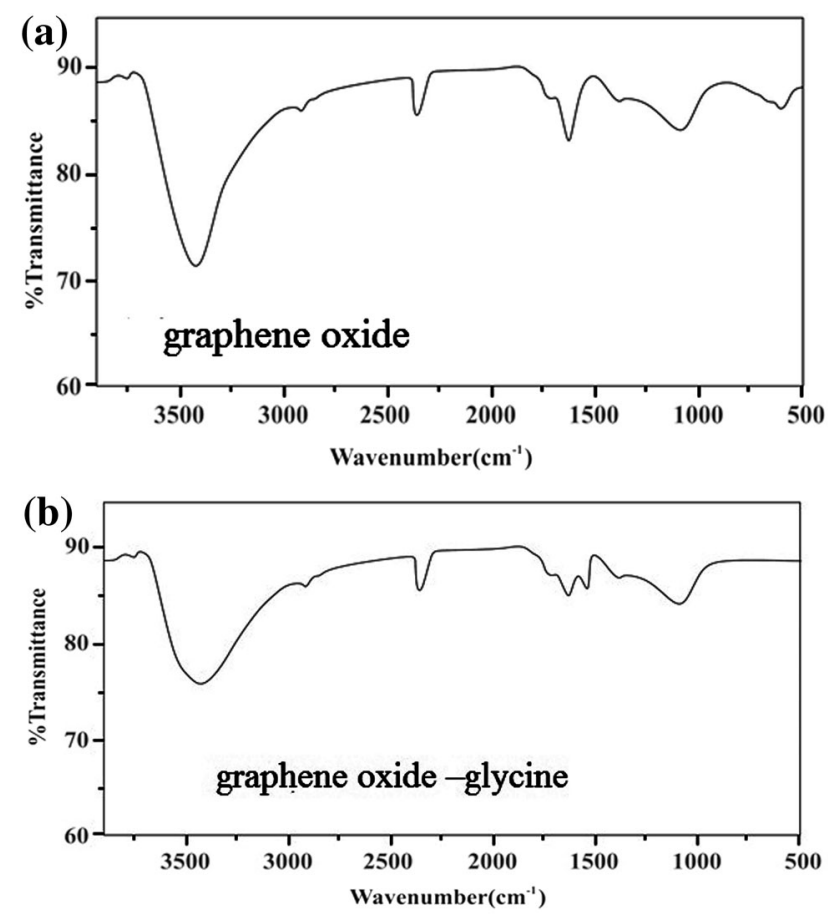

Fig. 1 FT-IR for functionalized graphene oxide (a) and graphene oxide-glycine (b)

respectively. Also, we can see aromatic $\mathrm{C}=\mathrm{C}\left(1622 \mathrm{~cm}^{-1}\right)$, carboxyl C-O $\left(1414 \mathrm{~cm}^{-1}\right)$, epoxy C-O $\left(1228 \mathrm{~cm}^{-1}\right)$ and $\mathrm{C}-\mathrm{O}\left(1116 \mathrm{~cm}^{-1}\right)$. After synthesis, nanocomposite $\mathrm{GO}-\mathrm{G}$, aliphatic C-H stretching vibrations at 2944 and $2889 \mathrm{~cm}^{-1}$ and an amide band at $1641 \mathrm{~cm}^{-1}$ in the FT-IR spectroscopy were seen [4]. TGA and SEM are presented (shown) in Figs. 2 and 3, respectively. With regard to TGA, the thermal gravimetric was increased on adding glycine to GO. The main reason related to the bonding between the carboxyl group $(\mathrm{COOH})$ on the $\mathrm{GO}$ surface and amine in glycine is that we can see new bonding in the nanocomposite.

\section{Contact time at removal of $\mathrm{Zn}(\mathrm{II})$ ions}

In the study of the adsorption process, one of the important factors is contact time. In this study, adsorption experiments occurred at several times: 10, 20, 30, 40, 50, 60 and $70 \mathrm{~min}$. Figure 4 shows the effect of contact time on the adsorption of $\mathrm{Zn}$ (II) ions on graphene oxide and functionalized $\mathrm{GO}-\mathrm{G}$ adsorbents. Results showed that the adsorption capacity increased with the increase in time. After $50 \mathrm{~min}$, the changes in the removal of $\mathrm{Zn}$ (II) ions were very slow; therefore, $50 \mathrm{~min}$ was determined as optimum time for adsorption of $\mathrm{Zn}$ (II) ions on graphene oxide and functionalized $\mathrm{GO}-\mathrm{G}$ adsorbents at $298 \mathrm{~K}$ and pH 6. 
Fig. 2 TGA for functionalized graphene oxide (a) and graphene oxide-glycine (b)

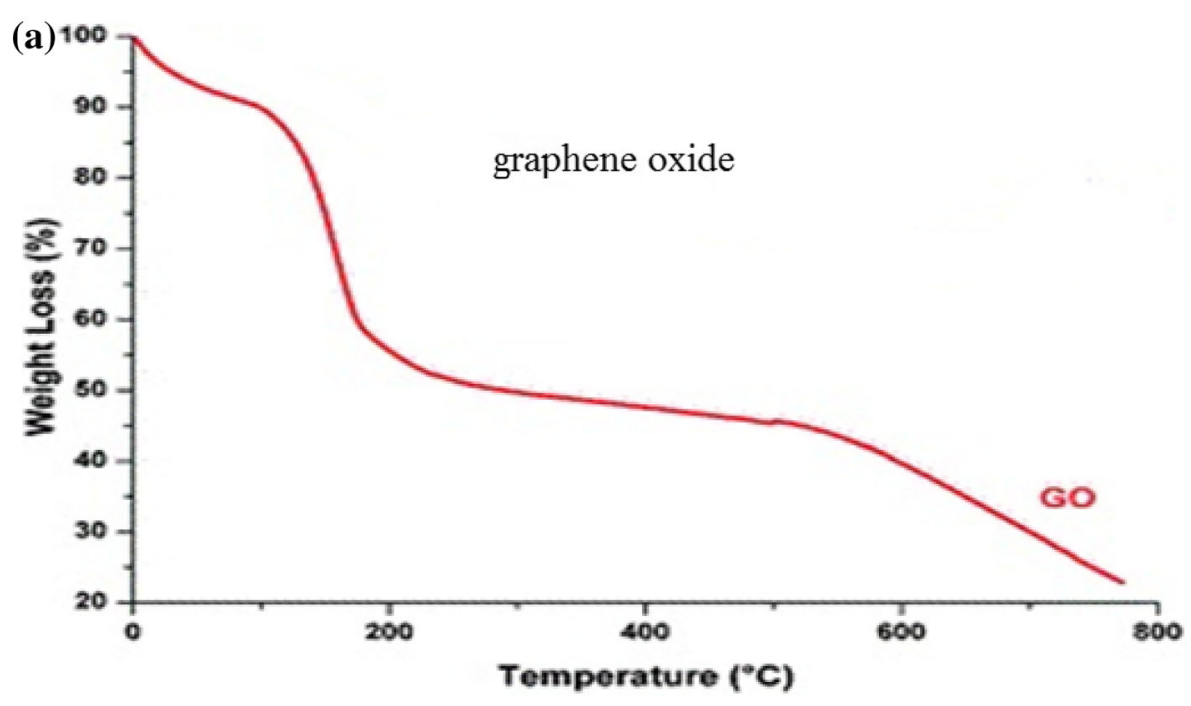

(b)

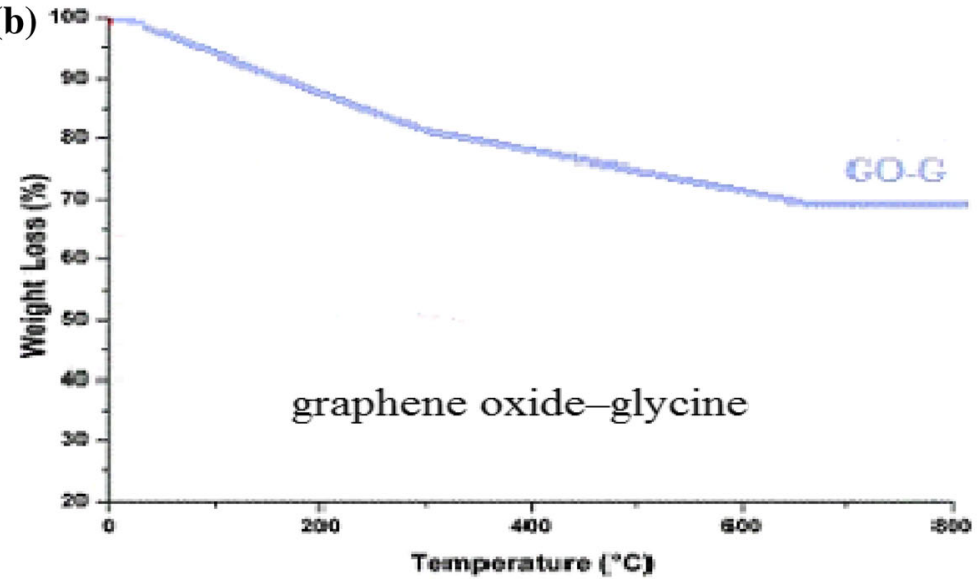

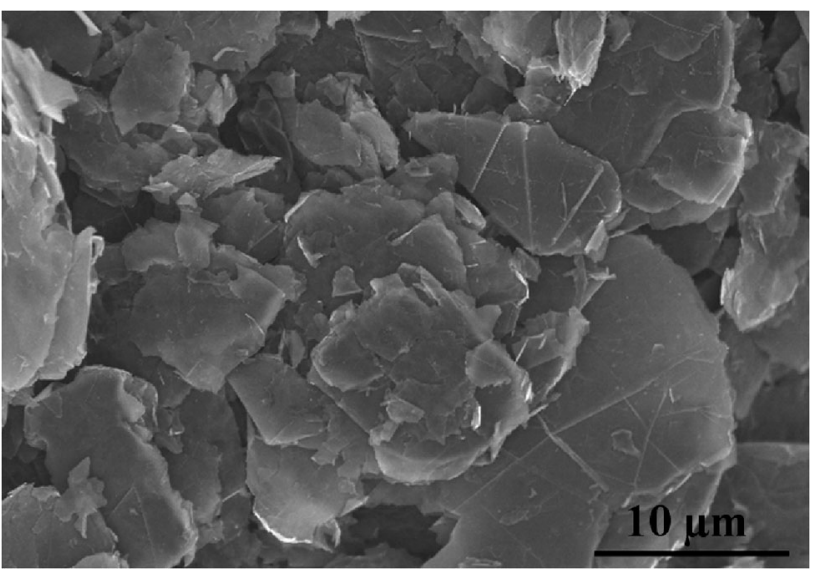

Fig. 3 SEM for graphene oxide surfaces

\section{Effect of initial $\mathrm{Zn}(\mathrm{II})$ ion concentration}

Adsorption of $\mathrm{Zn}(\mathrm{II})$ ions by graphene oxide and functionalized GO-G surfaces was performed at different initial concentrations of $\mathrm{Zn}$ (II) ions at 10, 15, 20 and $25 \mathrm{ppm}, \mathrm{pH}$
6, temperature $298 \mathrm{~K}$ and $50 \mathrm{~min}$. Figure 5 shows that with increasing the initial concentration of zinc ions from 10 to $25 \mathrm{mg} \mathrm{L}^{-1}$, the removal of $\mathrm{Zn}$ (II) ions was increased. The results indicate that there are higher attractive forces between $\mathrm{Zn}(\mathrm{II})$ ions and graphene oxide and functionalized GO- $\mathrm{G}$ adsorbents, because the surfaces of adsorbents would be as well besieged by $\left(\mathrm{H}_{3} \mathrm{O}^{+}\right)$ions which elevate ion interactions with binding sites of the surface of adsorbents [12].

\section{Adsorption kinetics study}

The kinetics of the adsorption process is a features that may strongly constrain the use of the adsorbent. The small kinetics adsorption significantly enlarges the removal time, which makes the adsorption inadequate [13]. In this study, we used the pseudo-first-order and four types of pseudo-second-order kinetic models to test the experimental data of removal of $\mathrm{Zn}(\mathrm{II})$ ions from aqueous solutions. 
Fig. 4 Effect of contact time on the removal of $\mathrm{Zn}$ (II) ions by graphite oxide and

functionalized graphene oxideglycine. $C_{0} 15 \mathrm{mg} / \mathrm{L}$ of $\mathrm{Zn}(\mathrm{II})$ ion solution; temperature: $298 \mathrm{~K}$ at $\mathrm{pH} 6$

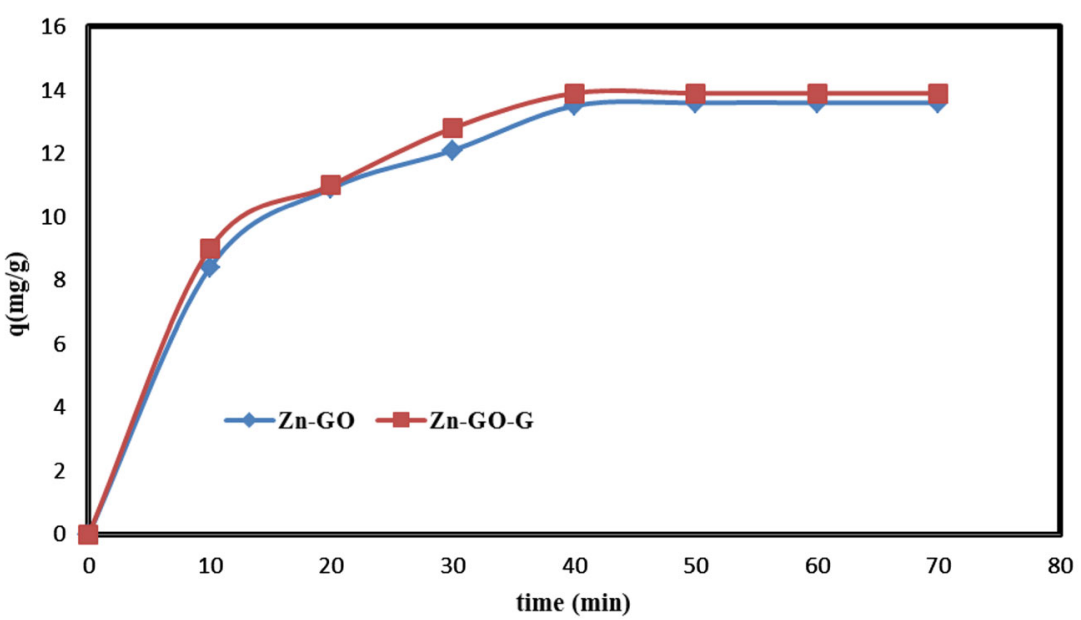

Fig. 5 Effect of concentration on the removal of $\mathrm{Zn}(\mathrm{II})$ ions by graphite oxide and functionalized graphene oxideglycine. $C_{0} 10-25 \mathrm{mg} / \mathrm{L}$ of $\mathrm{Zn}(\mathrm{II})$ ions solution; time: $50 \mathrm{~min}$ at $\mathrm{pH} 6$

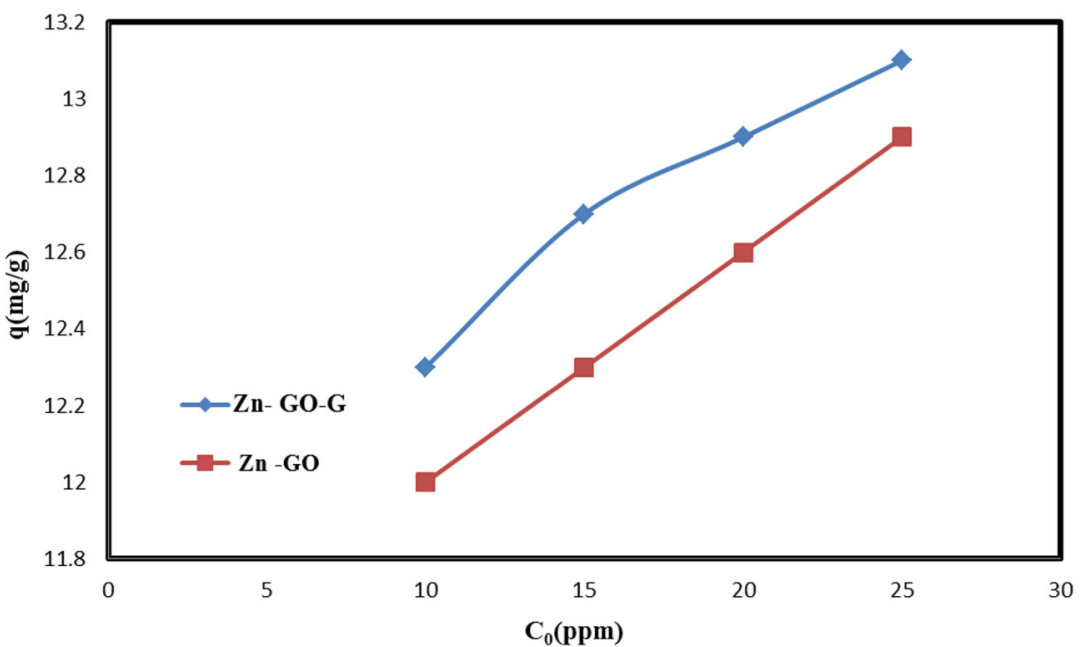

\section{The pseudo-first-order kinetic model}

The pseudo-first-order kinetic model is more suitable for low concentrations of solute [14]. The liner form of the pseudo-first-order equation is explained as follows [15]:

$\log \left(q_{\mathrm{e}}-q_{t}\right)=\log \left(q_{\mathrm{e}}\right)-k_{1} t$

where $q_{\mathrm{e}}\left(\mathrm{mg} \mathrm{g}^{-1}\right)$ is the amounts of $\mathrm{Zn}(\mathrm{II})$ ions adsorbed on graphene oxide and functionalized $\mathrm{GO}-\mathrm{G}$ equilibrium, $q_{t}\left(\mathrm{mg} \mathrm{g}^{-1}\right)$ is the amount of $\mathrm{Zn}(\mathrm{II})$ ions adsorbed on graphene oxide and functionalized GO-G at time $t$, and $k_{1}$ is the rate constant, determined by plotting $\ln \left(q_{\mathrm{e}}-q_{t}\right)$ versus $t$ (Fig. 6; Table 1).

\section{The pseudo-second-order kinetic model}

Ho presented a pseudo-second-order rate law expression in 1995 that explained how the rate depended on the adsorption equilibrium capacity but not on the concentration of the adsorbate [16]. In the adsorption process used, the change in concentration of an adsorbent or the adsorption unit time determined the adsorption rate. The kinetic rate equations can be explained as follows:

$\frac{\mathrm{d} q_{t}}{\mathrm{~d} t}=k\left(q_{\mathrm{e}}-q_{t}\right)^{2}$.

An integrated pseudo-second-order rate law can be obtained from Eq. (4) for the boundary conditions $t=0$ to $t=t$ and $q_{t}=0$ to $q_{t}=q_{t}$, and is given by [16]:

$\frac{1}{\left(q_{\mathrm{e}}-q_{t}\right)}=\frac{1}{q_{\mathrm{e}}}+k t$.

Equation (5) can be rearranged to obtain a linear form:

$\frac{t}{q t}=\frac{1}{k_{2} q_{\mathrm{e}}^{2}}+\frac{t}{q_{\mathrm{e}}}$,

where $t$ (min) is the adsorption time; $q_{t}\left(\mathrm{mg} \mathrm{g}^{-1}\right)$ the amount of adsorbate at time $t ; q_{\mathrm{e}}\left(\mathrm{mg} \mathrm{g}^{-1}\right)$ the amount of adsorbate at equilibrium; $k_{2}\left(\mathrm{~g} \mathrm{mg}^{-1} \mathrm{~min}^{-1}\right)$ the equilibrium rate constant of pseudo-second-order adsorption. 
Fig. 6 Plot of the pseudo-firsorder adsorption kinetics of $\mathrm{Zn}$ (II) ions on graphite oxide and functionalized graphene oxide-glycine. $C_{0} 15 \mathrm{mg} / \mathrm{L}$ of $\mathrm{Zn}(\mathrm{II})$ ion solution; temperature: $298 \mathrm{~K}$ at $\mathrm{pH} 6$

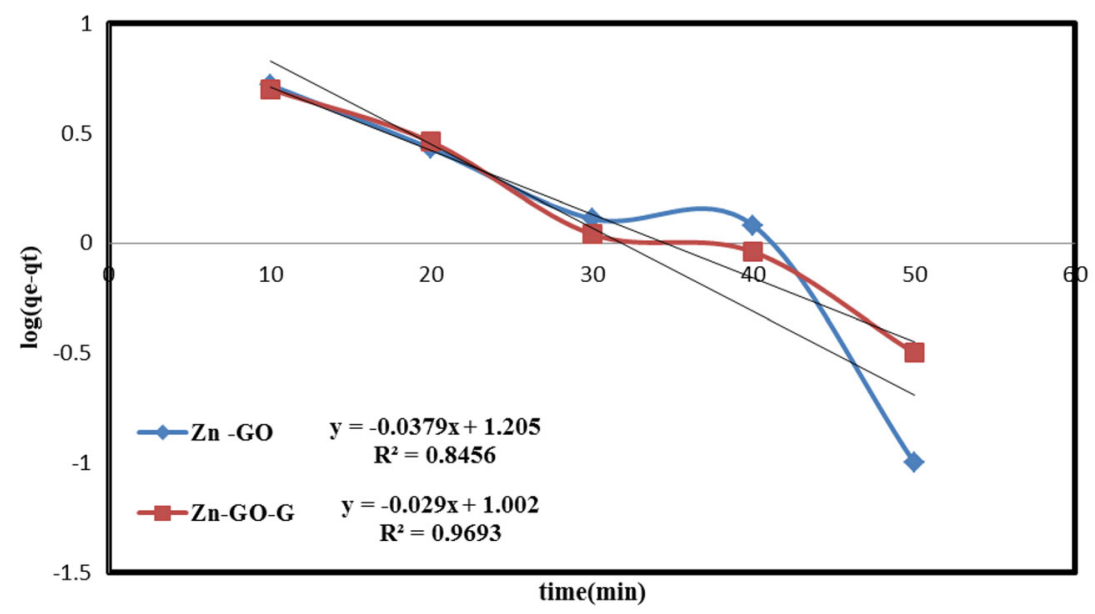

Table 1 Langmuir isotherm parameters and $X^{2}$ parameter for adsorption of $\mathrm{Zn}$ (II) ions on $\mathrm{G}$ and GO-G surfaces, $C_{0} 15 \mathrm{mg} /$ $\mathrm{L}$ of $\mathrm{Zn}(\mathrm{II})$ solution; temperature: $298 \mathrm{~K}$ at $\mathrm{pH} 6$

\begin{tabular}{|c|c|c|c|c|}
\hline \multirow[t]{2}{*}{ Isotherm } & \multirow[t]{2}{*}{ Equation } & \multirow[t]{2}{*}{ Parameters } & \multicolumn{2}{|l|}{ Adsorbent } \\
\hline & & & GO & GOG \\
\hline \multirow[t]{4}{*}{ Langmuir 1} & \multirow{4}{*}{$\frac{C_{\mathrm{e}}}{q_{\mathrm{e}}}=\frac{1}{K Q_{\mathrm{m}}}+\frac{C_{\mathrm{e}}}{Q_{\mathrm{m}}}$} & $Q_{\mathrm{m}}\left(\mathrm{mg} \mathrm{g}^{-1}\right)$ & 88.12 & 95.41 \\
\hline & & $K_{1}\left(\mathrm{~L} \mathrm{mg}^{-1}\right)$ & 0.070 & 0.063 \\
\hline & & $R_{\mathrm{L} 1}$ & $0.20-0.44$ & $0.3-0.4$ \\
\hline & & $R^{2}$ & 0.9592 & 0.9870 \\
\hline \multirow[t]{4}{*}{ Langmuir 2} & \multirow{4}{*}{$\frac{1}{q_{\mathrm{e}}}=\frac{1}{Q_{\mathrm{m}}}+\frac{1}{K Q_{\mathrm{m}} C_{\mathrm{e}}}$} & $Q_{\mathrm{m}}\left(\mathrm{mg} \mathrm{g}^{-1}\right)$ & 31.32 & 32.13 \\
\hline & & $K_{2}\left(\mathrm{~L} \mathrm{mg}^{-1}\right)$ & 1.03 & 1.04 \\
\hline & & $R_{\mathrm{L} 2}$ & $0.02-0.04$ & $0.01-0.04$ \\
\hline & & $R^{2}$ & 0.9913 & 0.9927 \\
\hline \multirow[t]{4}{*}{ Langmuir 3} & \multirow{4}{*}{$q_{\mathrm{e}}=Q_{\mathrm{m}}-\frac{q_{\mathrm{e}}}{K C_{\mathrm{e}}}$} & $Q_{\mathrm{m}}\left(\mathrm{mg} \mathrm{g}^{-1}\right)$ & 2.910 & 3.009 \\
\hline & & $K_{3}\left(\mathrm{~L} \mathrm{mg}^{-1}\right)$ & 2.923 & 1.770 \\
\hline & & $R_{\mathrm{L} 3}$ & $0.01-0.03$ & $0.01-0.03$ \\
\hline & & $R^{2}$ & 0.9846 & 0.9785 \\
\hline \multirow[t]{4}{*}{ Langmuir 4} & \multirow[t]{4}{*}{$\frac{q_{\mathrm{e}}}{C_{\mathrm{e}}}=K Q_{\mathrm{m}}-K q_{\mathrm{e}}$} & $Q_{\mathrm{m}}\left(\mathrm{mg} \mathrm{g}^{-1}\right)$ & 13.599 & 11.251 \\
\hline & & $K_{4}\left(\mathrm{~L} \mathrm{mg}^{-1}\right)$ & 2.898 & 4.180 \\
\hline & & $R_{\mathrm{L} 4}$ & $0.01-0.03$ & $0.01-0.03$ \\
\hline & & $R^{2}$ & 0.9681 & 0.9253 \\
\hline
\end{tabular}

Four types of the pseudo-second-order models were defined as [17, 18]:

$\frac{t}{q_{\mathrm{e}}}=\frac{1}{k_{2} q_{\mathrm{e}}^{2}}+\frac{1}{q_{\mathrm{e}}} t$,

$\frac{1}{q_{\mathrm{e}}}=\frac{1}{q}+\left(\frac{1}{k_{2} q_{\mathrm{e}}^{2}}\right) \frac{1}{t}$,

$q_{\mathrm{e}}=q_{t}-\left(\frac{1}{k q_{t}}\right) \frac{q}{t}$,

$\frac{q_{\mathrm{e}}}{t}=k q_{t}^{2}-k q_{\mathrm{e}} q_{t}$.

The results showed that the values of the correlation coefficients $\left(R^{2}\right)$ for type (I) of the pseudo-second-order kinetic model are closest to 1 for both adsorbents, much higher than the correlation coefficients derived from the pseudo-first-order and type II, type III and type IV of the pseudo-second-order kinetic models. These results suggest that adsorption of $\mathrm{Zn}(\mathrm{II})$ ions on graphene oxide and functionalized GO-G adsorbents in compliance with type (I) of the pseudo-second-order kinetic model (Figs. 7, 8, 9, 10).

\section{Conclusions}

In this work, adsorption of $\mathrm{Zn}$ (II) ions by graphene oxide and functionalized GO-G were examined at $298 \mathrm{~K}$ and $\mathrm{pH}$ 6. Optimal time for the adsorption process was selected at $50 \mathrm{~min}$, because we did not have a substantial increase in the adsorption capacity of $\mathrm{Zn}$ (II) ions on graphene oxide and GO-G after $50 \mathrm{~min}$. The effect of the initial concentration of zinc ions in the aqueous solution was studied, and 
Fig. 7 Plot of the pseudosecond-order (type I) adsorption kinetic of $\mathrm{Zn}$ (II) on graphite oxide and functionalized graphene oxide-glycine. $C_{0}$ $15 \mathrm{mg} / \mathrm{L}$ of $\mathrm{Zn}(\mathrm{II})$ solution; temperature: $298 \mathrm{~K}$ at $\mathrm{pH} 6$

Fig. 8 Plot of the pseudosecond-order (type II) adsorption kinetic of $\mathrm{Zn}$ (II) ions on graphite oxide and functionalized graphene oxideglycine. $C_{0} 15 \mathrm{mg} / \mathrm{L}$ of $\mathrm{Zn}(\mathrm{II})$ ion solution; temperature:

$298 \mathrm{~K}$ at $\mathrm{pH} 6$

Fig. 9 Plot of the pseudosecond-order (type III) adsorption kinetic of $\mathrm{Zn}$ (II) ions on graphite oxide and functionalized graphene oxideglycine. $C_{0} 15 \mathrm{mg} / \mathrm{L}$ of $\mathrm{Zn}(\mathrm{II})$ ion solution; temperature:

$298 \mathrm{~K}$ at $\mathrm{pH} 6$
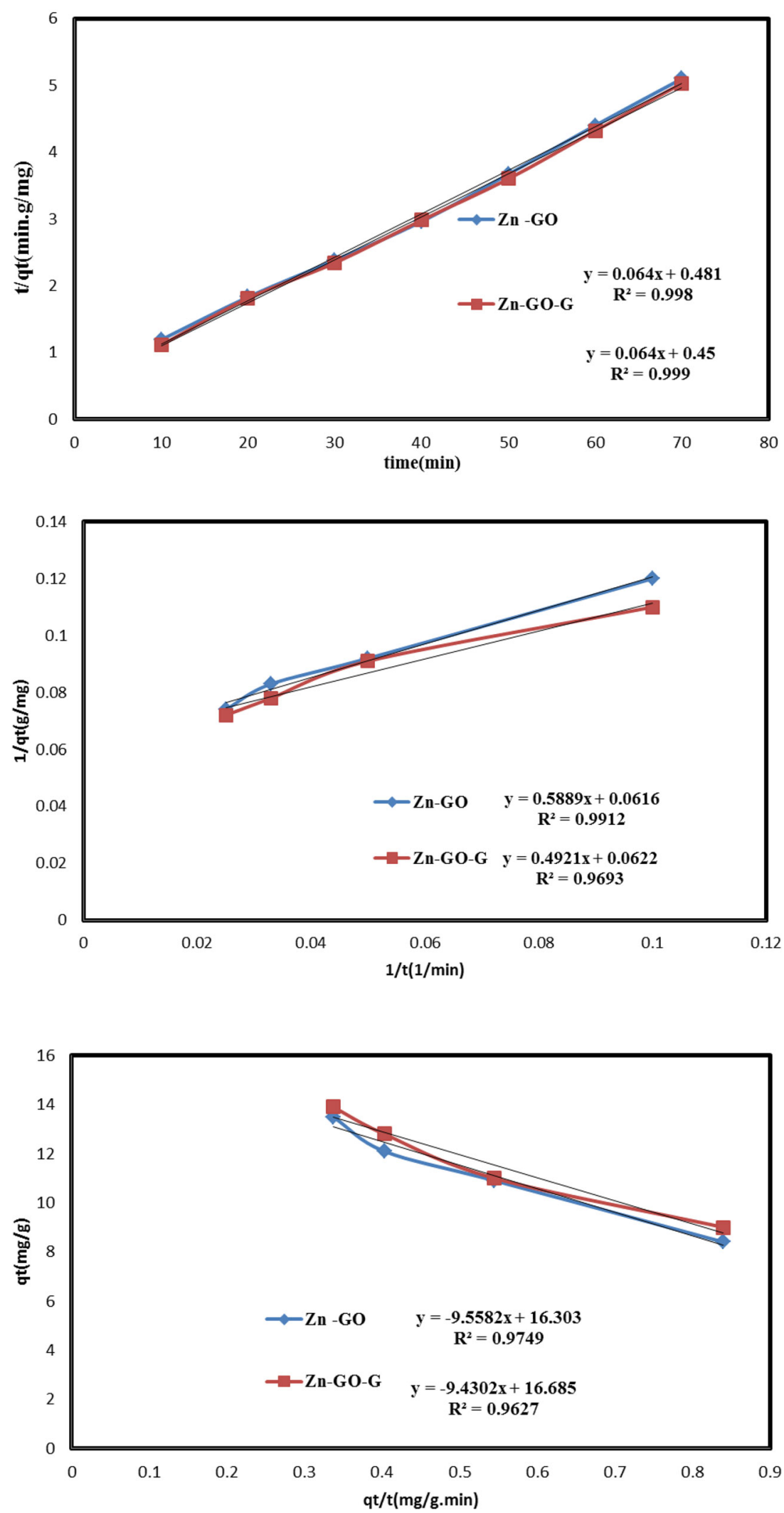

the results showed that the adsorption capacity was increased with increase in the initial concentration of $\mathrm{Zn}$ (II) ions. The pseudo-first-order and four types of the pseudo- second-order kinetic models were used to test the experimental data, and the results suggest that adsorption of $\mathrm{Zn}$ (II) ions on adsorbents followed type (I) of the pseudo- 
Fig. 10 Plot of the pseudosecond-order (type IV) adsorption kinetic of $\mathrm{Zn}$ (II) ion on graphite oxide and functionalized graphene oxideglycine. $C_{0} 15 \mathrm{mg} / \mathrm{L}$ of $\mathrm{Zn}(\mathrm{II})$ ion solution; temperature: $298 \mathrm{~K}$ at $\mathrm{pH} 6$

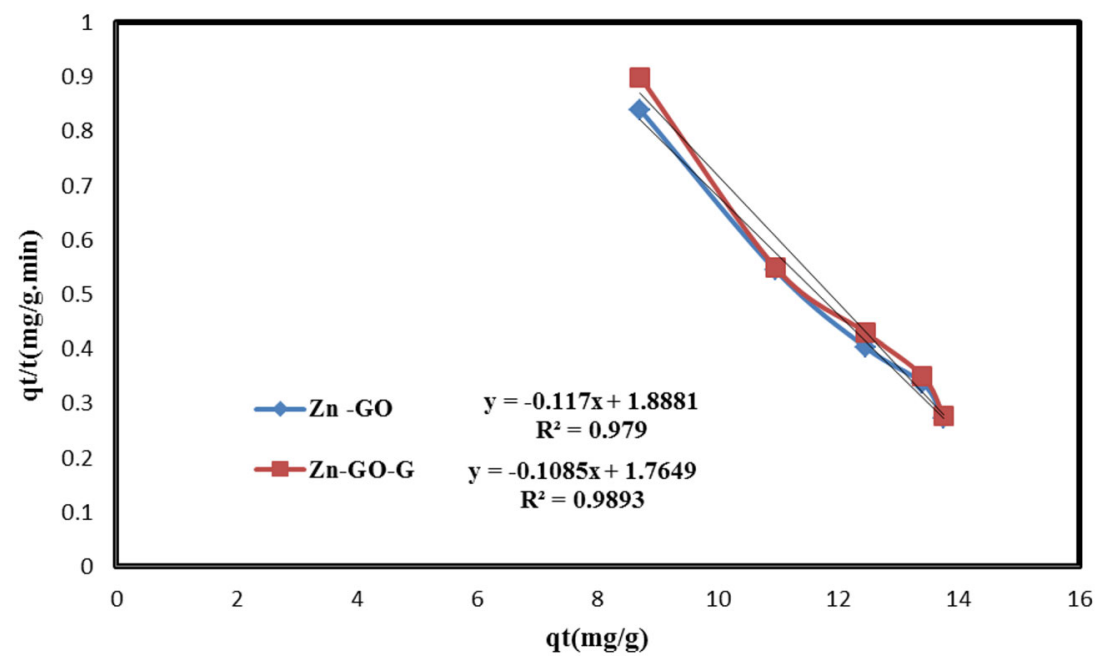

second-order kinetic model because of the higher value of $\left(R^{2}\right)$.

Acknowledgments The author would like to thank the Islamic Azad, Roudehen Branch for their financial support.

Open Access This article is distributed under the terms of the Creative Commons Attribution 4.0 International License (http:// creativecommons.org/licenses/by/4.0/), which permits unrestricted use, distribution, and reproduction in any medium, provided you give appropriate credit to the original author(s) and the source, provide a link to the Creative Commons license, and indicate if changes were made.

\section{References}

1. Ren, X., Shao, D., Yang, S., Hu, J., Sheng, G., Tan, X., Wang, X.: Comparative study of $\mathrm{Pb}(\mathrm{II})$ sorption on $\mathrm{XC}-72$ carbon and multiwalled carbon nanotubes from aqueous solutions. Chem. Eng. J. 170, 170-177 (2011)

2. Tian, Y., Gao, B., Morales, V.L., Wu, L., Wang, Y., MuñozCarpena, R., Cao, C., Huang, Q., Yang, L.: Methods of using carbon nanotubes as filter media to remove aqueous heavy metals. Chem. Eng. J. 210, 557-563 (2012)

3. Sharan-Liew, Y., Josephjand, C.G., HOW, S.: Biosorption of lead contaminated wastewater using cattails (Typhaangustifolia) leaves: kinetic studies. J. Serb. Chem. Soc. 76, 1037-1047 (2011)

4. Sadowski, Z.: Effect of biosorption of $\mathrm{Pb}$ (II), $\mathrm{Cu}$ (II) and $\mathrm{Cd}(\mathrm{II})$ on the zeta potential and flocculation of Nocardia sp. Miner. Eng. 14, 547-552 (2001)

5. Tarase, M.V., Zade, A.B., Gurnule, W.B., Resin, I.: Synthesis, characterization, and ion-exchange properties of terpolymer resins derived from 2,4-dihydroxypropiophenone, biuret, and formaldehyde. J. Appl. Polym. Sci. 108, 738-746 (2008)

6. Shrestha, S., Son, G., Lee, S., Lee, T.: Isotherm and thermodynamic studies of $\mathrm{Zn}(\mathrm{II})$ adsorption on lignite and coconut shellbased activated carbon fiber. Chemosphere 92, 1053-1061 (2013)

7. Al-Tohamia, F., Ackachab, M.A., Belaidc, R.A., Hamaadi, M.: Adsorption of $\mathrm{Zn}$ (II) ions from aqueous solutions by novel adsorbent: Ngella sativa seeds. Sciverse. Scien. Cedirect. 5, 400-404 (2013)
8. Ye, X., Du, Y., Lu, D., Wang, C.: Fabrication of cyclodextrincoated poly (diallyldimethylammonium chloride)-functionalized graphene composite film modified glassy carbon-rotating disk electrode and its application for simultaneous electrochemical determination colorants of sunset yellow and tartrazine. Anal. Chim. Acta 779, 22-34 (2013)

9. Algothmi, W.M., Murthy Bandaru, N., Yu, Y., Shapter, J.G., Ellis, A.V.: Alginate-graphene oxide hybrid gel beads: an efficient copper adsorbent material. J. Colloid Interface Sci. 397, 32-38 (2013)

10. Wu, Q., Feng, C., Wang, C., Wang, Z.: A facile one-pot solvothermal method to produce superparamagnetic graphene$\mathrm{Fe}_{3} \mathrm{O}_{4}$ nanocomposite and its application in the removal of dye from aqueous solution. Colloid Sur. B 101, 210-214 (2013)

11. Ai, L., Jiang, J.: Removal of methylene blue from aqueous solution with self-assembled cylindrical graphene-carbon nanotube hybrid. Chem. Eng. J. 192, 156-163 (2012)

12. Machado, F.M., Bergmann, C.P., Fernandes, T.H.M., Lima, E.C., Royer, B., Calveteb, T., Faganc, S.B.: Adsorption of reactive red $\mathrm{M}-2 \mathrm{BE}$ dye from water solutions by multi-walled carbon nanotubes and activated carbon. J. Hazard Mater. 192, 1122-1131 (2011)

13. Ramana, D.K.V., Yu, J.S., Seshaiah, K.: Silver nanoparticles deposited multiwalled carbon nanotubes for removal of $\mathrm{Cu}$ (II) and $\mathrm{Cd}(\mathrm{II})$ from water: surface, kinetic, equilibrium, and thermal adsorption properties. Chem. Eng. J. 223, 806-815 (2013)

14. Zhang, X., Cheng, C., Zhao, J., Maa, L., Sun, S., Zhao, C.: Polyethersulfone enwrapped graphene oxide porous particles for water treatment. Chem. Eng. J 215, 72-81 (2013)

15. Leng, Y., Guo, W., Su, S., Yi, C., Xing, L.: Removal of antimony(III) from aqueous solution by graphene as an adsorbent. Chem. Eng. J. 211, 406-411 (2012)

16. Ho, Y.: Pseudo-isotherms using a second order kinetic expression constant. Adsorption 10, 151-158 (2004)

17. Robati, D.: Pseudo-second-order kinetic equations for modeling adsorption systems for removal of lead ions using multi-walled carbon nanotube. J. Nanostruct. Chem. 3, 55 (2013)

18. Dora, T.K., Mohanty, Y.K., Roy, G.K., Sarangi, B.: Adsorption studies of As(III) from wastewater with a novel adsorbent in a three-phase fluidized bed by using response surface method. J. Environ. Chem. Eng. 1, 150-158 (2013) 